Conference Paper

\title{
Models for Research in Art, Design, and the Creative Industries
}

Liggett, S., Earnshaw, R.A., Cunningham, S., Heald, K., and Thompson, E.

This is a paper presented at the Internet Technologies and Applications (ITA-15), 8-11 Sept 2015, Glyndŵr University, Wrexham, UK. doi: 10.1109/ITechA.2015.7317457

Copyright of the author(s). Reproduced here with their permission and the permission of the conference organisers.

\section{Recommended citation:}

Liggett, S., Earnshaw, R.A., Cunningham, S., Heald, K., and Thompson, E. (2015) 'Models for Research in Art, Design, and the Creative Industries'. In: Proc of Internet Technologies and Applications (ITA15), 8-11 Sept 2015, Glyndŵr University, Wrexham, UK. doi: 10.1109/ITechA.2015.7317457 


\title{
Models for Research in Art, Design, and the Creative Industries
}

\author{
R. A. Earnshaw ${ }^{1}$, S. Liggett ${ }^{1}$, S. Cunningham ${ }^{1}$, K. Heald ${ }^{2}$, E. Thompson ${ }^{1}$ and P.S. Excell ${ }^{1}$ \\ ${ }^{1}$ Glyndwr University, Wales, UK \\ \{r.earnshaw, s.liggett, s.cunningham, e.thompson, p.excell\}@glyndwr.ac.uk \\ ${ }^{2}$ Bangor University \\ K.Heald@ bangor.ac.uk
}

\begin{abstract}
Research in art and design involves the knowledge and understanding associated with creative works. Practice-led research is also an integral part of art and design. All these areas have been subject to ongoing discussion and debate. One of the current challenges is to produce models that facilitate and enable the development and advancement of research within art and design. However, these models must also synchronise with institutional, national and international frameworks for research development, evaluation, and assessment. The latter can have implications for faculty advancement and also formulaic allocations of research funding across the sector. Practice-led and practice-based research have also generated substantial discussion in terms of seeking a consensus on what is appropriate for developmental purposes and academic assessment. In addition, this area also needs evaluation methods which are fair and consistent across different types of practice. The current situation is that works in these areas are assessed, various types of metric are compared and evaluated, and a proposal is made for the inclusion of metrics alongside the development and use of research models for the development of research. It is argued that deeper analyses of, and more enlightened interdisciplinary approaches to, this are clearly needed.
\end{abstract}

Keywords- Research models; research development; research assessment; practice-led research; research metrics; altmetrics

\section{INTRODUCTION}

Research may be defined as "the systematic investigation into, and study of, materials and sources in order to establish facts and reach new conclusions" [1]. Its outcome is therefore a contribution to knowledge and an advancement in understanding in the field in which the research is done. The degree of originality of the research is normally determined by a peer review process which results in publication in refereed conferences, journals, or exhibitions. Research in science and technology is characterised by experimental and analytical processes involving the testing of hypotheses and the determination of conclusions. In general, these are quantitative processes. Research in art and design often involves more qualitative processes but the work done is subject to both critical assessment and peer review. Thus creative works in art and design are expected to contribute to an advancement of knowledge and refinement of technique in the field.

Frayling [2] distinguished three distinct kinds of research in art and design: research into art and design, research through art and design, and research for art and design.

Research into art and design may include the following -

- Historical research

- Aesthetic or perceptual research

- Research into theoretical perspectives such as social, ethical, and cultural factors

Research through art and design may involve -

- Materials research such as that involved in pigments, metalwork, ceramics, and jewellery

- Development work - such as using a device in a new way (e.g. Hockney and the iPad - see Fig. 1 [3])

- Action research - a write-up of experimental practical work in a studio, including any design considerations which preceded the setup of the experiments

This can lead to a degree with the outputs verified mainly by project work, whether at undergraduate or postgraduate level.

Research for art and design may include the gathering of research materials, and the production of an artefact. This may include -

- The visual exhibition and communication of artefacts

- The cognitive tradition in fine art

- The expressive outcomes

This area is less easy to evaluate in terms of possible academic outcomes and deliverables, and is the subject of ongoing discussion.

"Arts and humanities research changes the ways in which we see the world - the past world, the present world and the world of the future. It enhances understanding of our times, our capacities and our inheritance". 
"It explores forms of identity, behaviour and expression, and seeks out new ways of knowing what it means to be human in different societies and across the centuries". [4]

Books, films, videos, radio documentaries, and exhibition catalogues are more common as outputs rather than journals as in science and engineering, though journals are used as well.

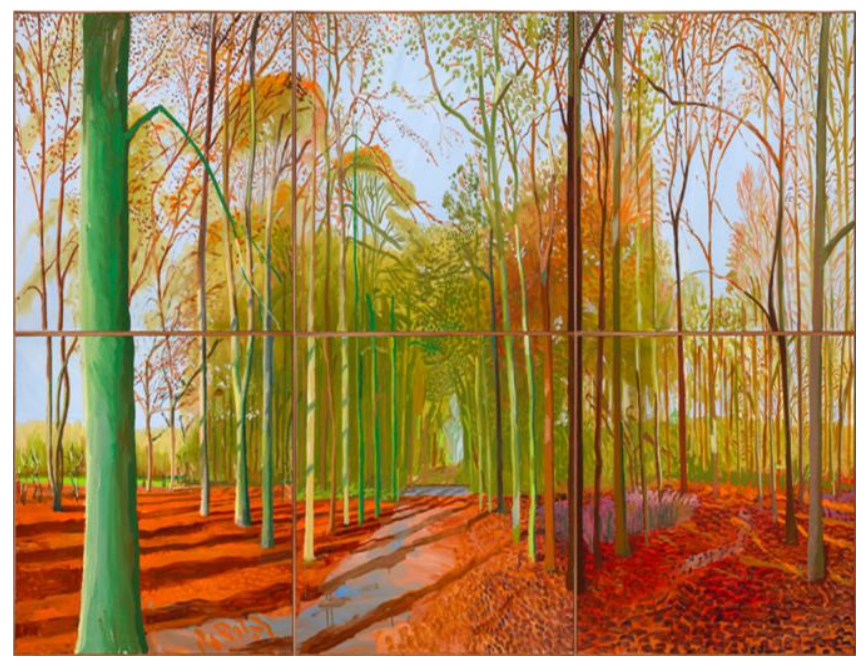

Fig. 1. Multiple drawings by David Hockney on iPad aggregated into one picture

\section{Research In ART AND DESIGN}

Art and design may comprise one or more of the following principal elements, broadly defined -

- Fine arts

- Arts and crafts

- Creative industries

- Critical, historical, social and cultural studies

- Museums and curatorship

- Visual and material culture

More detail is provided in the definitions associated with Unit of Assessment (UOA) 34 in the REF2014 specification [5]: this has the formal title "Art and Design: History, Practice and Theory".

In addition, there is often opportunity to combine the above areas (and other areas outside art and design) by means of cross-disciplinary research collaborations. It is often at the boundaries between existing disciplines and traditions where new areas of research and practice are able to develop. These often raise challenges as they can question the status quo and blur the boundary lines between traditional disciplines, and possibly associated resourcing. Also, science and technology are increasingly being recognised as having significant contributions to make, either in providing state of the art tools and facilities to support the research environments where art works can be designed and created, or in the design, implementation and delivery of creative artefacts and services (as in creative industries).
Creative industries may utilise many forms of technology but their content always depends on the ideas and creativity of those who design and produce it. It is being increasingly recognised that this is a rich source of value and enterprise. If current industries become increasingly dependent on the generation of new kinds of information and content in order to maintain market share, then there will be an increasing requirement for those with creative skills.

Following the research evaluation of RAE2008, the Art and Design Panel issued an overview report [6] summarising all the submissions which included the following -

"There were a large number of outputs characterised by interdisciplinary practice, artist/curator projects and collaborations, installation, moving image, lens- and textbased work. At its best, the fine art submitted for assessment displayed an understanding of the contextual framework needed for a research assessment exercise, with a depth of evidence and corroborating material that helped present the research in the round"

"The sub-panel was most impressed by narratives that included clearly described strategies and structures that were firmly embedded in the research culture and were linked to concrete detail".

Therefore models for the development and assessment of research in art and design need to be sufficiently flexible to encompass traditional work, and also encourage and facilitate new kinds of work that may cut across existing disciplines, bring in new disciplines, or challenge current traditions and practices.

Following the research evaluation of REF2014, the Art and Design Sub-Panel issued an overview report [7] summarising all the submissions which included the following -

"Third, art and design is the largest sector for the production of research through practice, and as such is a leader in the elaboration of emergent approaches to knowledge. Fourth, the sector has become one of the most important for the development of innovative and productive interdisciplinary research. The connection of the arts with the sciences, and of history and theory with museums and galleries, to cite two examples, reveals the complex, dynamic and impactful condition of research in the sector. Fifth, the environment exists in abundance for the conducting of world class research in art and design".

This emphasises the continuing significance of interdisciplinary research and research through practice.

\section{PRACTICE-LED RESEARCH}

Practice-led research has become widespread in art and design because of the nature of the variety of processes involved in producing creative works. However, an agreed model of operation and evaluation which reflects the diverse fields has 
yet to be fully agreed. The Arts and Humanities Research Council in the UK performed an investigation into practice-led research in the fields of art, design and architecture [8]. One conclusion was that for these fields "conventional ideas of contribution to knowledge or understanding may not be serving us well". This was felt to be particularly true for fine art practice where it "indicated a need to develop new models to encourage the growth of practice-led research". There was a recognition that the debate was currently "dominated by the question of outputs, characterised by arguments about the admissibility of artefacts in place of conventional texts" [8].

Therefore how is new knowledge created in practice-led research? Sullivan discusses [9] how 'facing the unknown and disrupting the known is precisely what artist researchers achieve as they delve into theoretical, conceptual, dialectical and conceptual practices through artmaking'. The search for, and impact on, new knowledge currently places responsibilities on the artist-researcher, challenging them to theorise their practice to self, others and communities. It is no longer possible for artist-researchers in academe to 'hide behind the role of the mute artist' [10]. For practice-led researchers it is therefore no longer feasible to borrow methods from other disciplines as this denies artist researchers 'intellectual maturity of arts practice as a plausible basis for raising significant theoretical questions and as a viable site for undertaking important artistic, cultural and educational enquires' [9].

By investigating and comparing different approaches and methods the artist researcher can make informed decisions to proceed. The aim of this methodological approach is to comprehend the process over the product of inquiry.

"Artistic research can never be characterised by a well-defined, rigid methodology. Rather, its form of research could be described as a methodical: it entails a strong belief in a methodological articulable result founded by operational strategies that cannot be legitimized beforehand. Indeed, that is the essential characteristic of artistic research" [11].

Regarding methodological innovations in Art and Design, it has been proposed 'if no established methodologies exist then invent them!' [12].

As well as discussion of the definitions of research in art and design, there is also a current trend towards the application of practice-led research. Attention in recent years by funding bodies has not only been on research, but also on assessing the economic and cultural value of research outputs for society, industry and commerce. The evaluation of the impact of research work at REF2014 was done using a number of case studies [13] and measured the degree of reach and significance of the work included in each of the case studies submitted. This implies that the research outputs included within each case study had to have a degree of applicability to, and recognition by, one or more aspects of the wider business and societal environment. Thus for art and design, such case studies included creative works in a variety of forms.

This was the first time that measurements of the impact of research work had been attempted, though previous research assessments have included both direct and indirect measures of this such as could be accomplished by evaluating such aspects as patents, citations in news media, industrial recognition, and economic significance. To provide greater externality at REF2014, evaluations of impact were also performed by key representatives of local government, publishing, arts non-governmental organisations, the design industries and the public museum service. However, it is still not certain how accurate or useful such measures are when determining the longer term value of research.

The University and College Union published an online petition against including impact in the evaluation of research which attracted 17,570 signatories in just over seven weeks. This included six Nobel laureates, eighty Fellows of the Royal Society and over three thousand professors. There was concern that the impact elements could detrimentally affect support for basic research across all disciplines, as well as possibly disproportionately disadvantaging research in the arts and humanities [14]. This follows on from mandates from the UK research councils which have required the inclusion in all grant proposals of an impact summary detailing information on who might benefit from the research and how an economic return could be secured. One effect of this may be to focus research on aspects of the field which can deliver more immediate-term financial benefits, at the expense of longer term research which could be more important, but with returns that are inevitably more difficult to quantify in advance.

The Step-change for Higher Arts Research and Education (SHARE) network [15], supported by the European Commission, has advanced the agenda for artistic research by developing a collaborative network of partners. It has sought to demonstrate that it is possible to support "a range of practices that have not been exhaustively predetermined and co-opted by the current fashions of art, intellect and policy, while negotiating a language of accountability of outcomes, outputs and metrics" [16].

At the same time, a distinction may be drawn between practice-based research where a contribution is made to knowledge, and practice-led research where the research can lead to new understandings about art practice.

\section{ReSEARCh AND DEVElopMent In THE CREATIVE INDUSTRIES}

Creative industries are by definition closer to the market because they involve the generation of products and services which meet a customer requirement or business need, often in a globally competitive environment. Innovate UK's Creative 
Industries Strategy 2013-16 identifies three key themes offering innovation challenges and opportunities to drive growth for the UK's creative and digital businesses [17]. These are convergence, data and transaction. Convergence implies service interoperability is required across a variety of platforms and products to ensure customers are able to seamlessly access content and services. The growth of data increasingly requires digital ways of analysis and presentation in order for it to be useful for consumers and businesses. In addition, access to content requires metadata and open standards. Transaction processing involves digital currency and easy-to-use licensing and commerce.

These requirements are business-led in order to meet customer needs, with enabling support from research and development organisations and academia. The principal criteria for success are improvement of business efficiency and enabling the UK's creative industries to grow and develop. Nesta estimates that the creative industries employ around one in 20 of the UK workforce [18]. If those involved in the wider creative economy are also included, then the number is higher (approx. 2.5 million in total in the UK). Leading edge work performed in the creative industries also serves as an attractor for international companies to invest in the UK.

The creative industries face a unique mixture of both challenges and opportunities because of their mixture of disciplines and varied backgrounds of the practitioners and researchers. Working within their own particular disciplines, researchers will typically find it comfortable and familiar to develop and evaluate ideas and processes utilising the methodologies that are traditionally associated with, or are intrinsic to, their discipline. The challenges and opportunities occur where cross and interdisciplinary work takes place. This leads to two issues relating to research: firstly, how to effectively support and nurture cross and inter disciplinary research in the creative industries and secondly, how to measure success, impact and output in such research.

As an example, consider the collaboration between a computer scientist, musician and dancer. They may be working on a project to produce a piece of visual music: the musician writes and records (or performs) the music, the computer scientist develops algorithms to generate graphics and animated sequences related to the acoustic features of the music and the movement of the dancer, and the dancer performs and improvises dance in response to the music and the graphics. Such a scenario is certainly not a new one, demonstrating that when collaborations work, they can be successful. However, how are the research aspects measured? The musician and dancer would likely consider public performance of the music and dance in a theatre or concert hall as a measure of impact and may write reflectively about the successes and failures of the work. However, they may have different measures of impact: one may consider audience size and attendance important, whilst another may value reviews and critique by external person(s). The computer scientist's research background largely demands evidence-based, published in written form, such as journals and books. They will consider impact related to the readership and citation count of the publication.

There is clearly a solution where each independent person within the cross-disciplinary team can take their research activities forward, but this leads to each working again within their own domain. Therefore, we identify a significant challenge in the research community, to define and implement ways of producing and measuring research and its impact in a way that does not require the duplication of effort, and for otherwise successful creative teams to fracture at arguably the most important point of the research process.

\section{Metrics For Research in ART AND Design}

A HEFCE Workshop on 16 January 2015 reviewed the use of metrics for measuring research quality and research impact in the arts and humanities [19]. It was predicated on the observation that the degree of linkage between the use of metrics and research quality in the arts and humanities may be less certain than that already established for the mainstream science and technology areas. In the latter areas, preliminary results have already been published comparing the use of metrics (e.g. such as the Departmental or Research Group hindex for a particular research area) with the results of the peer reviewed research assessments in the UK at 2008 and 2014. For the latter, more work is still to be done but initial results present a fair degree of overall correlation between the use of metrics and the results published from REF2014 in core science and technology areas [20].

On the other hand, for the arts and humanities there may be a less well-accepted correlation between metrics such as paper citation count and/or journal impact factor and the results of the peer review process by a panel of experts in the field. Possible reasons for this could include the following factors publication is via many different forms and media; journal impact factors and citations rates are not yet fully accepted as a proxy for quality in the arts and humanities; half-lives of publications tend to be much longer than in science and technology; and monographs, works of art, and compositions may be more important from the $15^{\text {th }}$ century than a recent secondary source $[21,22]$. In science and technology, the latter is normally unlikely to be the case. Peer review processes in these areas generally check first of all that all the relevant and most recent work is cited in a publication to give confidence that the research published may be regarded as a new and distinctive advance on current knowledge.

A counter-argument is that for books and monographs there is a case for the academic standing and reputation of the publisher to be used as a proxy for quality - since there can be a demonstrated link between a rigorous editorial review process using reviewers of international standing, and the originality, rigour and significance of the work being 
submitted for publication. The latter characteristics originality, significance and rigour - are generally accepted internationally as a measure of research quality and degree of excellence, and were used as the primary criteria for assessing research outputs at REF2014 [5]. These were augmented at RAE2008 with an evaluation of the esteem factors of the researcher including recognition, influence and benefit. At REF2014 these have been replaced in part by Impact Case Studies. In addition, for books and monographs, Libcitations [23] has been proposed as an additional measure of value based on library data as an instrument for gauging the cultural significance and impact of books.

Of more significant interest is the fact that the changing patterns of publication are resulting in an overall framework which is in transition. Many researchers are increasingly using the Internet and web not only to initiate collaborations with other researchers, but also to demonstrate and publish their work and generate impact. Many use blogs and Twitter to circulate ideas and generate interest. The term altmetrics was introduced to cover not just citation counts but also any form of reference or impact, such as how many data and knowledge bases refer to it, article views, downloads, references in blogs, social media, and news media [24]. Thus they can be applied not only to papers and books, but also to new kinds of output more appropriate to the web such as data sets, presentations, videos, source, repositories and web pages. With the increasing emphasis on open access and the increasing demand of sponsors and funding agencies to require researchers to provide the data underlying their research work, researchers are now often required to publish their data sets in conjunction with their paper.

Thus traditional printed and digital publications are being increasingly augmented by -

- "The sharing of "raw science" like datasets, code, and experimental designs.

- Semantic publishing or "nanopublication," where the citeable unit is an argument or passage rather than entire article.

- Widespread self-publishing via blogging, microblogging, and comments or annotations on existing work" [20].

\section{CONCLUSIONS}

The increasing diversity of research outputs, and ways of evaluating them, provides an increasing opportunity for art, design and creative industries to engage effectively in the current discussion to ensure fair and equitable assessment of research quality in these areas, as well as their current and future resourcing. It is likely that existing methods of evaluation (possibly augmented by metrics) for core science and technology areas will continue in the short term for traditional research outputs (i.e. journal papers). However, the continued transition to the Internet and the availability of more real-time methods of evaluation will result in a changing landscape. Clark [25] argued that one Internet year is equivalent to seven calendar years, and therefore the more significant the Internet becomes, the faster the processes and developments associated with it will take place. Increasing selectivity in research and reductions in research funding imply that allocation of resource for research needs to be supported by evidence and cost-justified, and may no longer be allocated solely by formulae. It is possible therefore that real-time metrics will be used increasingly to monitor and review research progress and research quality, and also to provide navigation and management data for research development and delivery - on an individual, departmental, institutional, and national basis.

\section{REFERENCES}

[1] Oxford Dictionaries, 2015

http://www.oxforddictionaries.com/definition/english/research

[2] C. Frayling, Research in Art and Design, Royal College of Art, 1994.

http://www.transart.org/wp-content/uploads/group-

documents/79/1372332724-Frayling_Research-in-Art-andDesign.pdf

[3] D. Hockney, Exhibition at the Royal Academy, 2012. http://www.theguardian.com/artanddesign/2012/jan/22/davidhockney-bigger-picture-review

[4] AHRC Strategy, 2013-18, p5 http://www.ahrc.ac.uk/News-andEvents/News/Documents/AHRC-Strategy-2013-18.pdf

REF2014, Panel Criteria and Working Methods, 2012 http://www.ref.ac.uk/media/ref/content/pub/panelcriteriaandworkin gmethods/01_12_2D.pdf

RAE2008 Panel Overview Reports, 2008.

Points 14 and 18 (iv) for UoA 63 -

http://www.rae.ac.uk/pubs/2009/ov/

[7] REF2014 Panel Overview Reports, 2015. Point 29 in UoA 34 http://www.ref.ac.uk/media/ref/content/expanel/member/Main\%20 $\underline{\text { Panel\%20D\%20overview\%20report.pdf }}$

"Practice-led Research in Art, Design and Architecture - AHRC Review", Nov 2007.

http://arts.brighton.ac.uk/ data/assets/pdf file/0018/43065/Practic e-Led_Review_Nov07.pdf

G. Sullivan, "Making Space", In: H. Smith, and R. T. Dean (Eds) Practice-led Research, Research-led Practice in the Creative Arts, Edinburgh University Press, 2009.

[10] M. Mäkelä and S. Routarinne, "Connecting different practices", In: M. Mäkelä and S. Routarinne. (eds) The Art of Research: Research Practices in Art and Design, University of Art and Design Helsinki, Finland, 2006.

[11] H. Slager, "Art and Method", In: Elkins, J. (Ed) Artists with PhDs: On the new Doctoral Degree in Studio Art, Washington, New Academia Publishing, 2009. 
C. Gray, and J. Malins, Visualising Research: A Guide to the Research Process in Art and Design, Ashgate Publishing Limited, 2004

[13] REF2014, Assessment Criteria and Level Definitions, 2014 http://www.ref.ac.uk/panels/assessmentcriteriaandleveldefinitions/

\section{[14] $\quad$ http://www.ucu.org.uk/index.cfm?articleid=4207}

[15] Step-change for Higher Arts Research and Education (SHARE) http://www.sharenetwork.eu/

[16] M. Wilson and S. Van Ruiten, SHARE Handboook for Artistic Research Education, p2, 2013

http://www.sharenetwork.eu/resources/share-handbook

[17] Innovate UK's Creative Industries Strategy 2013-16. https://connect.innovateuk.org/documents/3220887/3676376/Creat ive\%20Industries\%20Strategy \%202013-2016?version $=1.0$

[18] Nesta, "A Manifesto for the Creative Economy", 2013. http://www.nesta.org.uk

[19] HEFCE Metrics Workshop: Metrics and the Assessment of Research Quality and Impact in the Arts and Humanities", 2015 http://www.hefce.ac.uk/news/events/2015/events99364.html

[20] “O. Mryglod, R. Kenna, Yu. Holovatch, B. Berche, "Predicting results of the Research Excellence Framework using departmental h-Index”, Scientometrics, Springer, 23 December 2014. http://link.springer.com/article/10.1007/s11192-014-1512-3

E. Welch, "Metrics in the Humanities: What are we Measuring?", HEFCE Workshop, 16 Jan 2015.

http://www.hefce.ac.uk/media/hefce/content/news/events/2015/hef cemetricsworkshopwarwick/Welch.pdf

E. Belfiore, 'Impact', 'value' and 'bad economics' : making sense of the problem of value in the arts and humanities". Arts and Humanities in Higher Education . ISSN 1474-0222, 2015. http://ahh.sagepub.com/content/14/1/95 http://ahh.sagepub.com/content/early/2014/04/22/14740222145315 03.refs

[23] H. D. White, S. K. Boell, H. Yu, M. Davis, C. S. Wilson and F. T.H. Cole, "Libcitations: A Measure for Comparative Assessment of Book Publications in the Humanities and Social Sciences", Journal of the American Society for Information Science and Technology, 60(6), pp. 1083-1096, 2009.

http://onlinelibrary.wiley.com/doi/10.1002/asi.21045/abstract

J. Priem, D. Taraborelli, P. Groth, C. Neylon, "Altmetrics: a Manifesto", 2010. http://altmetrics.org/manifesto/

J. Clark, Netscape Time: The Making of the Billion-dollar Start-up that Changed the World, St. Martin's Press, Inc, 1999.

\section{Biographies}

\section{Prof Rae Earnshaw}

Rae Earnshaw is Professor of Creative Industries at Glyndwr University. He gained his $\mathrm{PhD}$ at the University of Leeds. He was Dean of the School of Informatics at the University of Bradford (1999-2007) and Pro Vice-Chancellor (Strategic Systems Development) (2004-09). He has been a Visiting Professor at Illinois Institute of Technology, George Washington University, USA, and Northwestern Polytechnical University, China. He is a member of ACM, IEEE, CGS, and a Fellow of the British Computer Society and the Institute of Physics, and a recipient of the Silver Core Award from the International Federation for Information Processing, Austria. He has authored and edited 36 books on computer graphics, visualization, multimedia, art, design, and digital media, and published over 200 papers in these areas.

http://sites.google.com/site/raearnshaw/

\section{Dr Susan Liggett}

Susan Liggett is a practising painter and Reader in Fine Art at Glyndŵr University. She has a PhD from the University of Wales (2008), a Post Graduate Diploma in Painting (MA) from the Royal Academy Schools London (1994) and a BA (Hons) from Nottingham Trent University (1989). Her work explores personal memory within the genres of landscape, figure and still life painting. She also works on collaborative research projects using performance and film that investigates applications of the creative process.

www.Susanliggett.com

www.suite-studiogroup.co.uk

\section{Dr Stuart Cunningham}

Stuart Cunningham joined Glyndŵr University in 2003. He was awarded the BSc degree in Computer Networks in 2001, and in 2003 was awarded the MSc Multimedia Communications degree with Distinction, both from the University of Paisley (UK). In 2009 he was awarded the degree of $\mathrm{PhD}$ in Data Reduced Audio Coding by the University of Wales (UK). His research interests cover a broad range of computing and creative hybrids and include: audio compression techniques; human-computer interaction and audio for health and wellbeing; sound design; wireless network security; and the socio-economic impact of leadingedge technologies. Stuart is a Fellow of the British Computer Society (BCS) and Chartered IT Professional (CITP), Member of the Institution of Engineering \& Technology (IET) and Member of the Institute of Electrical and Electronics Engineers (IEEE). He currently serves on the BCS Computer Arts Society committee. Stuart was also a member of the MPEG Music Notation Standards (MPEG-SMR) working group.

\section{Prof Estelle Thompson}

Estelle Thompson is Professor of Fine Art and Head of the Business Division of Media, Arts and Design at Glyndwr University. She has a Post Graduate Degree (MA RCA) in Painting from the Royal College of Art, London (1986). She is a practising artist who has exhibited nationally and internationally including solo exhibitions at Oriel Sycharth Gallery, Wrexham (2014) Purdy Hicks, London, (1989 2009), Wetterling Gallery, Stockholm, (2004), The New Gallery, Walsall (2001), Rosenberg and Kaufman Fine Art, New York (2001) and Angel Row Gallery, Nottingham (2001). Selected group exhibitions include; Drawn Togetherartist as Selector, Jerwood Gallery, Hastings (2014), Head to Head, Standpoint Gallery, London (2014) detail, Usher Gallery, Lincoln (2015); Transition Gallery, London 
(2014); H-Galllery, Bangkok (2014), Colour as Material, Kuvataideakatemia, Helsinki (2013), Do You Believe in Angels?, Mo space, Manila (2014); Eqautor Art Projects, Singapore (2014), Small is Beautiful XXXI Who's Afraid of Red, Yellow and Blue?, Flowers Gallery, London (2013), The Theory and Practice of the Small Painting, Equator Art Projects (2013), Back and Forth, B55, Budapest (2012), Maquettes, Furnished space, London (2011), Calligrams, Eagle Gallery, London (2010), L'apres moderne, Project Midi, Brussels (2008) and Drawing Breath, Gallery 1, NAS Galleries, Sydney; NAFA Galleries, Singapore; Wimbledon Space, London; RWA, Bristol; Robert Gordon University Gallery, Aberdeen (2006-8). Collections include; Arts Council of Great Britain, British Council, British Museum, New York Public Library, Contemporary Arts Society, Towner Art Gallery, Ferens Art Gallery, Abbott Hall Art Gallery, Oldham Art Gallery, The New Art Gallery Walsall and Deustche Bank. As a painter her research concerns include visual perception, colour, chromatic and monochromatic theories, Sacred Geometry and two-dimensional geometry including the golden ratio, divine ratio and golden rectangle, compositional formats and spacial possibilities.

http://www.estellethompson.com/

\section{Prof Peter Excell}

Peter Excell is Deputy Vice-Chancellor and Professor of Communications at Glyndwr University. His interests cover computing, electronics, and creative industries, with a strong spirit of interdisciplinarity that is needed for the digital knowledge economy. He gained his BSc in Engineering Science at the University of Reading and $\mathrm{PhD}$ in Electronic Engineering at the University of Bradford. His work on future mobile communications devices is being carried out in conjunction with colleagues from wider discipline areas, analysing human communications in a holistic way and developing new ways of using mobile multimedia devices. He has published over 400 papers. He is a Fellow of the British Computer Society, the Institution of Engineering \& Technology and of the Higher Education Academy, a Chartered IT Professional and Chartered Engineer. He is also a member of the UK and Ireland committee of the IEEE Society on the Social Implications of Technology. http://www.glyndwr.ac.uk/en/StaffProfiles/PeterExcell/ 